Sophien Kamoun

The Ohio State University, Wooster

Christine D. Smart

Cornell University, Geneva, NY

\title{
Late Blight of Potato and Tomato in the Genomics Era
}

Tremendous progress in the availability of genomic data has been made in the past decade. With the advent of high throughput and affordable DNA sequencing, the entire hereditary blueprint of an organism can be determined. A widespread transition into research enabled by the tools and resources of genomics is consequently occurring, and it has already affected countless disciplines within the biological sciences, including plant pathology. This new era of research allows a comprehensive study of gene structure and function and has already delivered tremendous insights into the basic biology of living organisms. Genomics offers new opportunities for applied biological sciences and is poised to impact plant health and plant disease management.

More than 150 years have elapsed since Phytophthora infestans caused the Irish potato famine, but strategies for managing potato and tomato late blight often remain unsustainable and costly. In effect, $P$. infestans continues to cost billions of dollars annually through losses in potato and tomato production and increased fungicide costs $(15,45,47,48)$. In the United States and other developed countries, chronic use of chemicals to manage late blight reduces the profit margins of farmers and is not always successful. Most populations of the pathogen are resistant to metalaxyl (and the active enantiomer mefenoxam), which had previously been very successful for controlling $P$. infestans $(19,47)$. In developing countries, late blight also affects subsistence potato production. Recent epidemics in the 1990s, notably in eastern Europe, have caused significant losses in

Corresponding author: Sophien Kamoun, Department of Plant Pathology, Ohio Agricultural Research and Development Center, 1680 Madison Ave., Wooster 44691; E-mail: Kamoun.1@osu.edu, Website: http://www.KamounLab.net

DOI: 10.1094/PD-89-0692

(C) 2005 The American Phytopathological Society yield $(20,46)$. In 2003, potato production was nearly eliminated in Papua New Guinea, one of the few countries in the world that was previously free of the disease (4). Remarkably, the disease spread through the entire country within 2 months of first incidence. Disturbing reports predict that potato late blight will continue to cause food shortages and hunger in several parts of the world $(20,46)$.

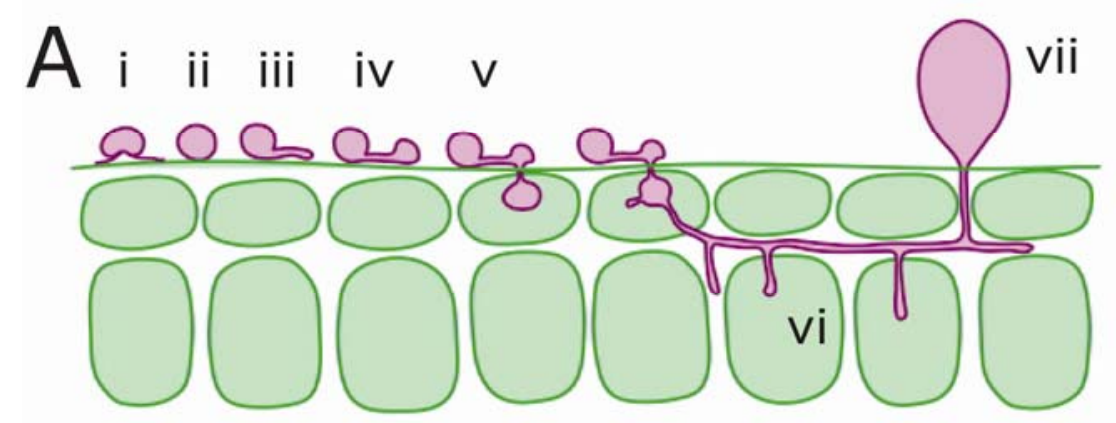

8

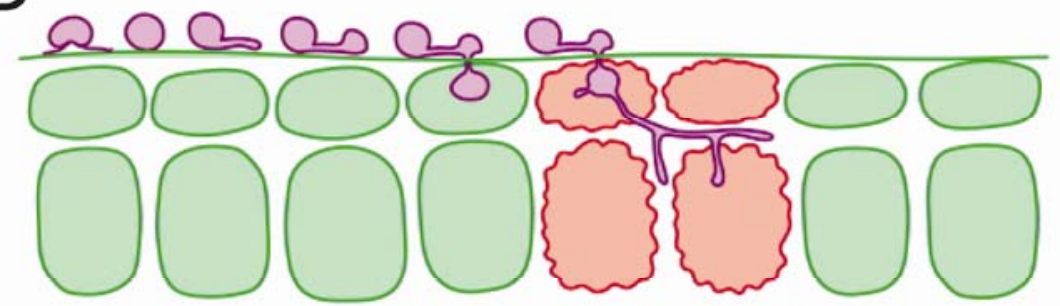

C

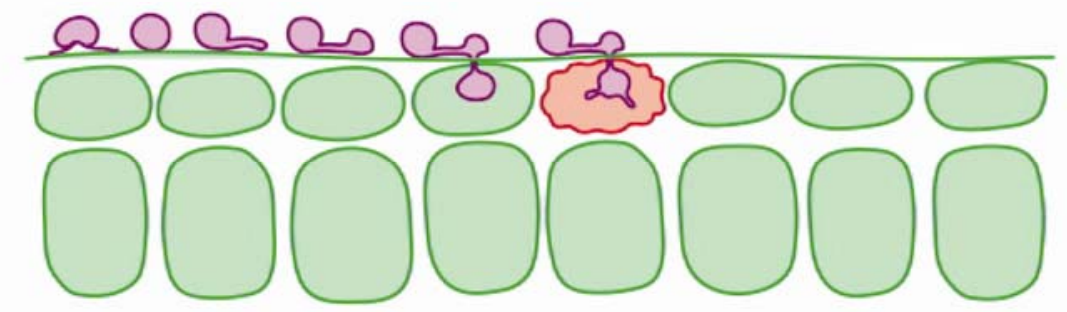

Fig. 1. Schematic view of infection cycle of Phytophthora infestans on A, susceptible, and $B$ and C, resistant plants. A, (i) zoospore, (ii) cyst, (iii) germinating cyst, (iv) germinated cyst with appressorium, (v) germinated cyst with appressorium and infection vesicle, (vi) haustorium, (vii) sporangium. B and C, Similar to panel A except that plant cells undergoing hypersensitive cell death are shown in red. The hypersensitive response can include groups of plant cells (B) or 1 to 2 cells (C) depending on the genotypes of plant and pathogen. 
The study of late blight has entered the genomics era $(11,33,44)$. Genome sequencing and the development of genomics-enabled technologies is proceeding not only for $P$. infestans but also for its primary host plants, tomato and potato (26). Although the technology of genomics is in its infancy, we are already experiencing the potential that it offers in understanding plant disease and improving plant health. The objective of this article is to illustrate the applications that genomics offer for managing potato and tomato late blight and to review how genomics has improved our understanding of $P$. infestans pathology.

\section{Introduction to $\boldsymbol{P}$. infestans}

$P$. infestans belongs to the oomycetes, a diverse group of eukaryotic microorganisms that includes pathogens of plants and animals, as well as saprophytic species (water molds) (31). The position of the oomycetes as a unique lineage of eukaryotes, unrelated to true fungi but closely related to heterokont (brown) algae and
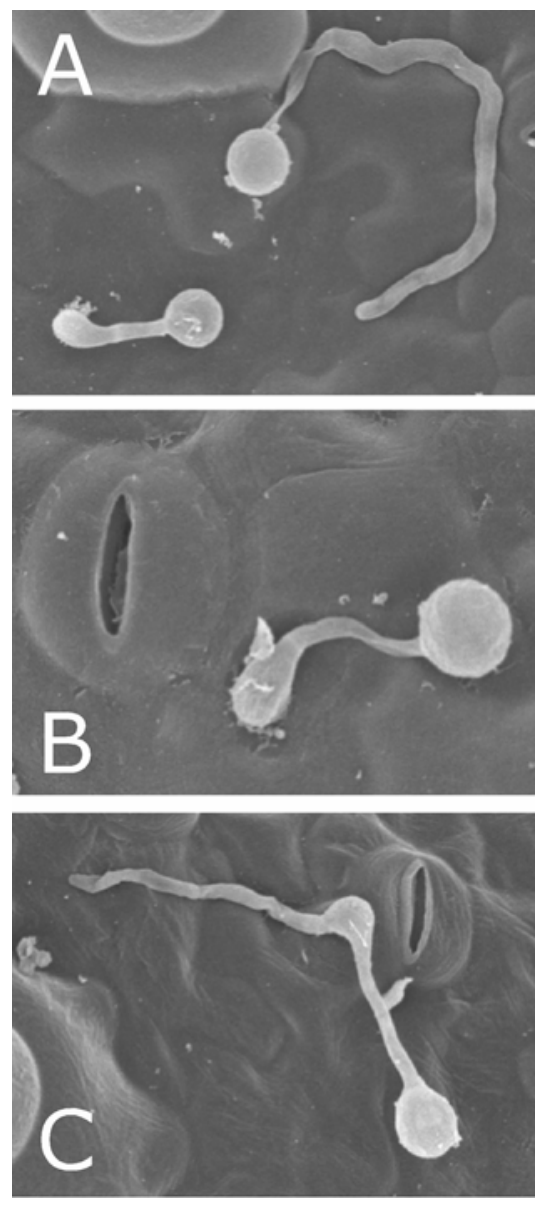

Fig. 2. Phytophthora infestans germlings on the surface of susceptible tomato leaves. A, Two germinated cysts with (left) and without (right) an appressorium. B, Germinated cyst with an appressorium. Note area of plant tissue degradation around the appressorium. C, Germinated cyst with appressorium-like structure that had failed in a penetration attempt. diatoms, is now well established based on molecular phylogenies and biochemical studies $(7,50)$. It is evident from these analyses that oomycetes evolved the ability to infect plants independently from other eukaryotic plant pathogens, including the "true" fungi, and are likely to have unique mechanisms to do so despite some apparent similarities $(31,37)$. The success of $P$. infestans and related species as plant pathogens possibly reflects this distinct evolutionary history. Also, basic biochemical differences between oomycetes and fungi exist and explain why oomycetes are insensitive to some fungicides. For example, chitin synthase inhibitors have no effect on $P$. infestans and other oomycetes since, unlike fungi, these organisms have little chitin in their cell wall (16).

$P$. infestans is a relatively specialized pathogen that causes disease on various tissues of potato and tomato crops (16). However, $P$. infestans was recently reported on a variety of species in the genus Solanum $(1,2,18,42)$, and reports of infection on nonsolanaceous plants are recurrent in the literature (16). Also, the closely related species Phytophthora mirabilis and Phytophthora ipomoeae infect plants as diverse as four-o'clock (Mirabilis jalapa) and morning glory (Ipomoea longipedunculata), respectively $(17,23)$. This suggests significant flexibility in adaptation to unrelated hosts in the $P$. infestans lineage.
$P$. infestans adopts a two-step infection style typical of hemibiotrophs. An early phase of infection, in which the pathogen requires living host cells, is followed by extensive necrosis of host tissue resulting in colonization and sporulation. Infection events and host responses following $P$. infestans attack are well understood at the cellular level $(13,61)$. Infection generally starts when motile zoospores that swim on the leaf surface encyst and germinate. Occasionally, sporangia can also initiate infections. Germ tubes form an appressorium and then a penetration peg, which pierces the cuticle and penetrates an epidermal cell to form an infection vesicle. Branching hyphae with narrow, digit-like haustoria expand from the site of penetration to neighboring cells through the intercellular space. Later on, infected tissue necrotizes and the mycelium develops sporangiophores that emerge through the stomata to produce numerous asexual spores called sporangia. Pathogen dispersal usually occurs through the sporangia, which release zoospores under cool and humid conditions (28). Resistance, whether displayed by host or nonhost plants, is frequently associated with the hypersensitive response (HR), a cell death defense response of plants $(34,61)$. The infection stages of $P$. infestans are illustrated in Figures 1 and 2. Examples of late blight symptoms on plants in potato and tomato fields are shown in Figures 3 and 4.
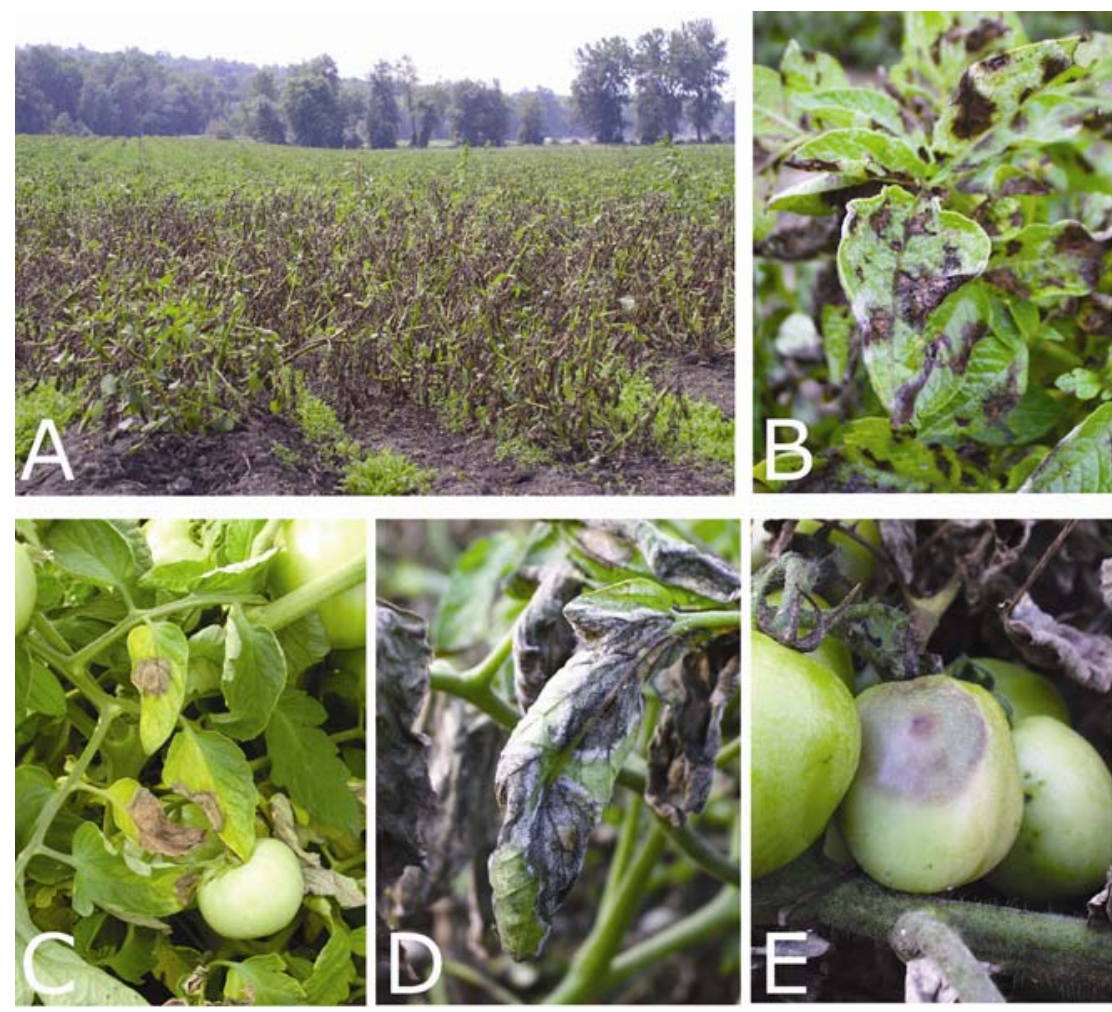

Fig. 3. Potato and tomato late blight in the field. A, One of many potato fields infected with Phytophthora infestans in New York in 2004. B, Late blight lesions on potato leaves. C, Moderate late blight lesions caused by a $P$. infestans isolate of the US8 clonal lineage on tomato leaves. D, Severe late blight lesions caused by a $P$. infestans isolate of the US17 clonal lineage on tomato leaves. Note heavy sporulation (whitish area). E, Late blight lesions on tomato fruit. 
For $P$. infestans to successfully infect and colonize its hosts, a series of pathogenic processes are necessary $(26,31)$. These include adhesion to plant surfaces, as well as penetration and colonization of host tissue. The molecular basis of these processes remains, in large part, poorly understood. However, the gene products that facilitate the infection process and mediate pathogenicity are being discovered at an unprecedented rate $(26,33,44)$. Pathogenesis involves the secretion of proteins and other molecules by $P$. infestans (26). Some of these participate in helping the pathogen attach to plant surfaces, while others help in breaking down physical barriers to infection, such as plant membranes or cell walls. Other molecules influence the physiology of the host by suppressing or inducing host defense responses.

A variety of pathogen molecules facilitate infection and colonization (virulence function) but also can be recognized by

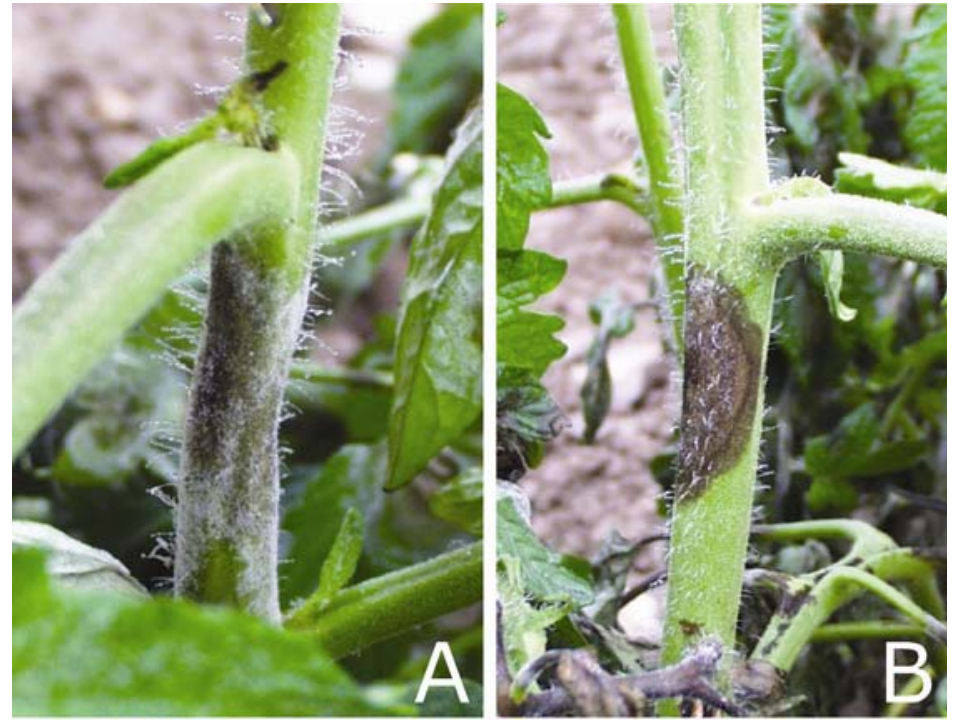

Fig. 4. Late blight lesions on the stems of A, susceptible, and B, partially resistant tomato cultivars.

\section{Genomics Glossary}

Bioinformatics -Application of computational analyses to large and complex sets of biological data.

cDNA -DNA sequence that is derived from a transcript (mRNA). mRNA needs to be transformed into a DNA molecule (cDNA) to allow cloning and other recombinant DNA manipulations.

Comparative genomics - Global comparison of gene content, structure, and evolution between different species.

Expression profiling - Large-scale analysis of changes in levels of gene expression. Expression profiling can be performed using a variety of techniques, including microarrays.

Gene expression - Conversion of the information coded by a gene into molecular activities that contribute to cellular functions. Gene expression typically refers to the transcription of genes (DNA) into transcripts (mRNA), followed by the translation of the transcripts into proteins.

Expressed sequence tag (EST) - A single-pass sequence of a cDNA. An EST usually consists of only part of the full-length transcript or cDNA sequence. ESTs are generated to allow rapid discovery of expressed genes.

Functional genomics - Translation of structural genomics data into an understanding of biological systems.

Genomics - Global study of the structure, function, and evolution of the genomes of living organisms.

Microarrays - Also known as gene chips; microarrays allow the simultaneous analysis of the expression of thousands of genes.

Mitochondrial genome - Genetic material of the mitochondrial organelle. The mitochondrial genome is distinct from the nuclear genome that is housed in the cell nucleus.

Proteomics - Global study of the structure and function of proteins.

Structural genomics - Study of the structure of the molecules that constitute a living organism, including its total set of genes, transcripts, and proteins.

host and/or nonhost plants (avirulence or elicitor function). These molecules have been defined as effectors $(26,58)$. In susceptible plants, effectors, encoded by pathogen virulence genes, promote infection by suppressing defense responses, enhancing susceptibility, or inducing disease symptoms. Alternatively, in resistant plants, effectors, encoded by pathogen avirulence (Avr) genes, are recognized by the products of plant disease resistance $(R)$ genes, resulting in the HR and effective defense responses. One central objective in studying the molecular basis of pathogenicity of $P$. infestans is to identify and functionally characterize effector genes. In this article, we will illustrate how this objective is greatly facilitated by genomics.

\section{What is Genomics?}

Genomics (or genome science) can be defined as the global study of the structure, function, and evolution of the genomes of living organisms (21). Structural genomics focuses on determining the molecular structure of the molecules that constitute a living organism, including its total set of genes, transcripts, and proteins. This is the "parts list" of a living organism. The challenge for modern genetics research is to translate this structural data into an understanding of biological systems. Functional genomics addresses this objective. Because it involves large and complex sets of data, genomics creates a challenge for biologists. Bioinformatics, the application of computational analyses to complex biological data sets, addresses this challenge. It is a crucial component of genomics that allows biologists to search, compare, and organize complex genomics data sets. The Sidebar lists some common terms used in genomics with brief descriptions.

\section{Update on Genomics of $P$. infestans}

Over the past decade, research interest in the late blight pathogen and other members of the genus Phytophthora has expanded among the scientific community. Increased awareness of the evolutionary history of oomycetes as unique eukaryotic microbes has led to specialization in oomycete genetics. Many molecular tools and methodologies developed for the study of true fungi cannot be applied to the study of oomycetes. However, an array of novel technological developments, including stable DNA transformation, use of reporter genes, and genetic manipulation using gene silencing, have facilitated the discovery and functional analyses of several oomycete genes (31).

Genetic research on oomycetes has entered another exciting phase with recent activities in genomics, functional genomics, and the resulting resources. Due to the massive genome size of $P$. infestans, which at $237 \mathrm{Mbp}$ is among the largest of all microbes (31), early efforts focused on 
cDNA sequencing and generated collections of expressed sequence tags (ESTs) from a variety of developmental, stress, and infection conditions $(33,44)$. So far, more than 75,000 ESTs have been generated, corresponding to about 18,000 genes (44). Genome sequencing, as well as the development of detailed genetic and physical maps, also is under way through work by a consortium of researchers led by the MIT Broad Institute and funded by the National Science Foundation (NSF) Microbial Genome Sequencing Program. Also, The Institute for Genomic Research (TIGR) completed the sequencing of three different mitochondrial genome types of $P$. infestans isolates, generating resources that will be invaluable to population studies ( $\mathrm{J}$. Ristaino, personal communication). Overall, these complementary efforts should lead to the sequencing of all the estimated 22,500 or so genes of $P$. infestans in the near future (44).

The $P$. infestans research community has already embarked into functional genomic analyses $(11,26,58)$. For example, computational tools and algorithms have been developed to mine sequence data sets for genes predicted to function in virulence and host-specificity, or to form targets for chemical control $(26,32)$. High throughput expression profiling and proteomic analyses are underway (9; P. van West, personal communication). Rapid assays for testing $P$. infestans genes in planta for elicitor function and virulence factor activity are well established (26). Typically, functional genomics involves a series of discrete steps, organized in a high-throughput pipeline, that allow researchers to link a particular sequence to a function or a trait.

\section{Applications of Genomics to $P$. infestans}

Potato and tomato growers frequently raise a recurrent set of questions about late blight. Although we do not have the answers to all these questions, in the future, genomics-enabled research will complement other areas of plant pathology research in helping to answer these questions. Indeed, there are many applications of genomics to basic and applied late blight pathology. Below, we review and illustrate a selection of the applications of genomics to late blight pathology and discuss the insights that genomics offers to some frequently asked questions.

How does late blight kill plants so quickly? The straightforward answer to this commonly raised question is that cool and wet weather conditions enable the pathogen population to explode, thus creating an enormous amount of inoculum in a very short period of time. While this answer is correct, it does not actually address the processes that zoospores undertake to infect plants and cause rapidly spreading lesions. Although the cytology of the in- fection process is well known $(13,61)$, the molecular mechanisms underlying pathogenicity remain largely unknown. Two areas in which genomics is providing a greater understanding of how $P$. infestans kills plants are highlighted below.

Identification of pathogenicity genes. A catalog of all the genes that make up $P$. infestans will greatly facilitate the identification of those genes that contribute to the infection process. Putative pathogenicity genes can be identified by similarity searches against known sequences in public databases. For example, many plant cell wall degrading enzymes, such as cutinases, polygalacturonases, pectate lyases, and cellulases, are highly conserved across organisms and are readily identified by sequence similarity searches $(39,44,59)$. In such cases, genomics allows facile cloning of the genes and offers a validation of prior knowledge accumulated through physiological or biochemical studies. In this example, numerous biochemical studies dating back to the 1960s have defined a variety of activities of cell wall hydrolytic enzymes in $P$. infestans extracts. However, the genes encoding such enzymes were only recently identified by similarity searches of sequence databases $(39,44,59)$.

Identification of novel pathogenicity processes. One of the most exciting prospects of genomics is its potential to unravel novel and totally unsuspected mechanisms of pathogenicity. Annotated gene sequences can serve as powerful hypothesis generators that can be pursued in laboratory experiments. For example, based on mining and annotation of sequence data of $P$. infestans, Tian et al. (57) hypothesized that $P$. infestans secretes proteins with inhibitory activity against plant proteases. One of these proteins, Extracellular Protease Inhibitor 1 (EPI1), was shown to contribute to virulence by inhibiting a defense protease of tomato, the pathogenesis-related protein $\mathrm{P} 69 \mathrm{~B}$ (57). This is an example of a novel insight that purely resulted from genomics (41). Indeed, there is emerging evidence that $P$. infestans deploys a variety of proteins that suppress host defense responses $(26,57)$. Some of these proteins inhibit plant enzymes, thus defeating plant defense activity. The identification of these molecules has created opportunities for biotechnological applications through the engineering of plant proteins that evade inhibition by $P$. infestans.

How does $P$. infestans overcome resistance genes so quickly, and can this be prevented? The cornerstone of disease management is the use of resistant crop cultivars. Unfortunately, durable resistance to late blight has not been available to growers, particularly in varieties that are in high demand by consumers. Recent research on both $P$. infestans avirulence (Avr) genes and potato disease resistance $(R)$ genes promises useful insight into this problem.
Strategies for isolating avirulence genes. More than a dozen late blight resistance genes ( $R$ genes) were introgressed into potato from the wild species Solanum demissum, S. bulbocastanum, and S. berthaultii using classical breeding (8). Cloning of some of these $R$ genes, notably $R 1$, $R 3 a$, and $R B$, has been achieved $(8,25,51)$. The genetics of $P$. infestans avirulence on $R$ gene-carrying potato lines revealed that avirulence is usually dominant. However, cloning of these Avr genes using positional (map-based) cloning methods has been slow due to adverse characteristics of Phytophthora, such as high levels of repetitive DNA and aberrant genetic segregation at the Avr locus. With genomics, novel strategies for isolating $P$. infestans Avr genes have emerged. For example, Bos et al. (12) described a strategy that combines data mining with intraspecific comparative genomics and functional analyses for the identification of novel $A v r$ genes from Phytophthora. This approach provides a rapid and efficient alternative to classical positional cloning strategies. Indeed, this strategy led to the cloning of the $P$. infestans Avr3a gene that is recognized by the $S$. demissum $R 3 a$ gene (5). The cloning of $A v r 3 a$ has improved our understanding of $P$. infestans race evolution and will provide DNA-based assays for typing pathogen races.

Novel uses of $R$ genes. Evidence exists that $R$ gene- $A v r$ gene interactions mediate several types of partial host resistance as well as nonhost resistance $(30,34,51)$. Although $R$ genes are thought to be ineffective in the field over long periods of time, there are plausible hypotheses that suggest that some of these genes could mediate durable resistance. For example, the $R B$ gene (also known as Rpi-blb1) of S. bulbocastanum recognizes a broad spectrum of $P$. infestans isolates and appears to be durable in the field $(24,51,60) . R$ genes, such as $R B$, could recognize an $A v r$ gene that is essential to the pathogen. Targeting a pathogen "Achilles heel" is expected to lead to durable resistance since mutations in the Avr gene would result in a severe fitness penalty for the pathogen. Other strategies may involve using an arsenal of $R$ genes that recognize a number of unrelated $A v r$ targets (14). The rationale is that an arsenal of $R$ genes could be difficult to overcome, as the pathogen would require multiple independent mutations to become virulent. Such genes can be bred or transformed into a single line ( $R$ gene pyramiding) or released as mixtures of cultivars that carry different $R$ genes ( $R$ gene polyculture) (14). To fully evaluate the potential of these strategies, rapid methods for cloning broad spectrum and nonhost $R$ genes and their target $A v r$ genes need to be developed. Several strategies facilitated by genomics, ranging from improved breeding procedures to novel functional assays, are being applied to this purpose (40). 
Why is the host range of $P$. infestans primarily restricted to potato and tomato? $P$. infestans is a relatively host-specific pathogen that does not infect major vegetable crops other than potato and tomato. The factors that determine the host range of $P$. infestans are currently unknown. Ongoing research on late blight and related pathosystems should help to unravel this mystery.

Host specificity of $\mathrm{P}$. infestans. Host specificity is a very active topic of research that is greatly benefiting from genomics. Some degree of specialization toward tomato, particularly among isolates of the US17 clonal lineage, has been noted (49). Other studies on host specificity are helping us to understand how nonhost plants resist $P$. infestans and the extent to which the mechanisms regulating nonhost resistance differ from host resistance $(27,30,35)$. Ultimately, this research will address questions such as the likelihood that the host range of $P$. infestans will increase, as well as offer novel biotechnological opportunities for engineering resistance in potato and tomato.

How does P. infestans differ from other Phytophthora spp.? Genome sequencing is taking place for several Phytophthora spp. besides $P$. infestans, including $P$. sojae and $P$. ramorum (Joint Genome Institute, Department of Energy). This will permit the use of comparative genomics, i.e., detailed comparisons of gene content and structure between different species. Ultimately, comparative genomics of Phytophthora will help determine why the host range of $P$. infestans appears more limited than that of other Phytophthora pathogens such as Phytophthora capsici, and why P. infestans infects potato whereas $P$. sojae infects soybean.

Where does the initial inoculum come from? In asexual populations, primary inoculum originates from infected seed tubers, cull piles, or volunteer plants that were infected the prior season. In addition, oospores in the soil or plant debris play important roles in initiating the disease in sexual populations. Genomics helps to improve our understanding of how inoc- ulum is formed through the study of genes that function in spore formation. Also, genome technology facilitates the development of novel tools for pathogen detection and identification. The spore stages of $P$. infestans are illustrated in Figure 5.

Spore biology. The spore stages of $P$. infestans, such as sporangia, zoospores, and oospores, play critical roles in the life and infection cycle of the pathogen, and greatly impact the epidemiology of the disease (28). Genomics offers the opportunity to understand the biology of spore structures at a detailed molecular level. For example, a large number of genes that are specifically expressed in spore stages were identified using a variety of expression profiling technologies $(3,36,54,55)$. These genes provide the tools to study spore dissemination, spore survival, and the impact of the sexual cycle on late blight pathology. This work also will lead to the development of molecular markers specific for the detection of spore stages in soil and plant tissue.

Pathogen detection and identification. The increased availability of DNA sequences of $P$. infestans improves our ability for early detection and identification of the pathogen. Target sequences that are appropriate for detection and identification can be selected from the genome sequence using computer methods. Judelson and Tooley (29) described a highly sensitive marker for $P$. infestans that is based on a $10,000 \times$ repeated sequence. Such primers combined with new technologies such as real-time PCR allow more sensitive screening of plant tissue and could even be applied for the in planta quantification of $P$. infestans biomass (27). The applications of such sensitive detection methods include screening of seed tubers to ensure pathogen-free material and improved identification of $P$. infestans strains and clonal lineages to facilitate population studies and help reconstruct epidemics.

How are $P$. infestans populations distributed and how do they evolve? New advances in population studies of $P$. infestans are made possible by the availability of genomic data. Such advances include the development of genetic markers and improved studies of pathogen gene evolution.

Molecular markers for population studies. Genomics greatly facilitates the development of molecular markers for studies of pathogen populations, for example by converting isozyme markers into DNA markers (43). So far, population studies of $P$. infestans have predominantly used markers that are selectively neutral (22). The data emerging from functional genomics studies will allow the development of a novel generation of markers that inform about the phenotype. Combined with classical neutral markers, these markers will allow assessments of the distribution and evolution of important phenotypic traits in $P$. infestans populations. A simple example consists of using information about Avr genes to develop genetic markers for following Avr alleles in $P$. infestans populations (5).

Understanding pathogen evolution. Mechanisms of molecular evolution of $P$. infestans genes and gene families are largely unknown. Identifying genomic regions of functional importance on which selection has acted will help to unravel the evolutionary genetic basis of ecological diversification in $P$. infestans. For example, diversifying selection (also known as positive selection) can be an indicator of genomic regions containing genes or gene families of functional importance. Genes affected by diversifying selection are important for pathogen fitness and therefore encode traits that are relevant to the pathology and management of the disease. Evidence of diversifying selection in effector genes could reflect an "arms race" of coevolution between the host and the pathogen. Liu et al. (38) used a combination of computer assisted data mining and sequence analysis of $P$. infestans isolates to identify $s c r 74$, a candidate effector gene that is highly polymorphic and under diversifying selection. The study of fastdiverging genes such as $s c r 74$ will help us understand the impact of natural selection on $P$. infestans evolution and population structure.
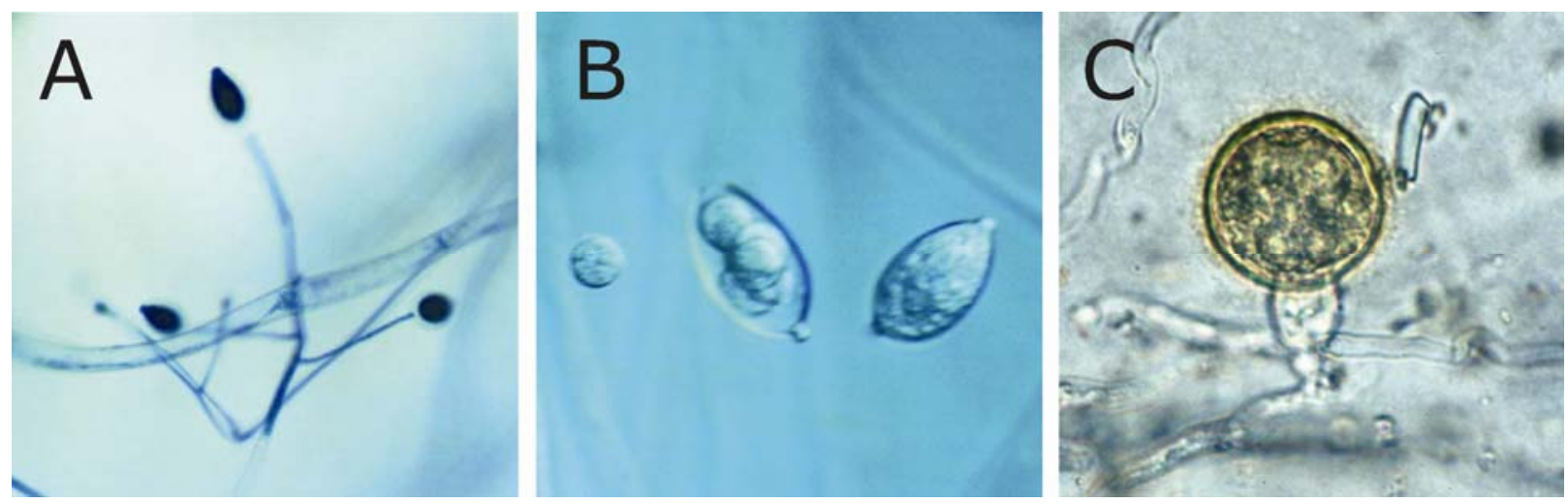

Fig. 5. Spores of Phytophthora infestans. A, Sporangiophores with oval-shaped sporangia stained with trypan blue. B, Zoospore (left), sporangium with differentiated zoospores (middle), and sporangium (right). C, Oospore. 
How long will it take $P$. infestans to acquire resistance to new fungicides? This question is common, as growers recall the devastation caused by the spread of resistance to the fungicide metalaxyl in the 1990s (19). Unfortunately, resistance to currently used fungicides, including dimethomorph, has been reported $(52,53)$. While it is difficult to know the exact lifespan of a fungicide, it is likely that resistance to other site-specific fungicides will develop. Genomics will accelerate the identification and detection of the specific mutations that confer fungicide resistance. Also, similar to work performed in the pharmaceutical industry, genomics may facilitate the identification of compounds for late blight control and improve our understanding of their mode of action.

Targets for chemical control. P. infestans genes that are essential for the survival and fitness of the pathogen are potential targets for chemical control. The protein corresponding to these putative target genes can be used in in vitro screens to identify inactivating chemicals. Such compounds can then be tested for their toxicity to $P$. infestans and their potential as fungicides. Although no currently commercialized fungicide was identified through a target gene approach, industrial research and development teams have adopted this strategy (56). Genomics provides sequences and tools to identify essential genes $(32,56)$. In $P$. infestans, since no routine functional assays for essential genes are available, candidate essential genes need to be identified by exhaustive annotation of the $P$. infestans genome. Genes that are conserved across a broad spectrum of plant pathogens, such as fungi and oomycetes, but are absent in plants and animals, form particularly attractive targets.

Mode of action of toxic chemicals. Genomics may contribute to studies on the mode of action of fungicides and other toxic compounds. For example, DNA microarray technology can be used to study the effect of toxic chemicals on $P$. infestans and classify these compounds based on the changes in gene expression they trigger in the microbe. This will help understand the mode of action of a particular compound and can lead to the identification of compounds that induce toxicity using novel mechanisms. The acquired knowledge will help to predict how long it will take before $P$. infestans becomes resistant to novel fungicides, and to devise optimal mixtures of chemicals that target different pathways in the pathogen, possibly delaying the emergence of resistant strains.

\section{Taking Genomics to the Field}

Opportunities exist to bring the science of genomics to the field. So far, the majority of genomic studies on late blight have been done in the laboratory in order to reduce variability and increase the oppor- tunity to identify small alterations in either the host or pathogen. However, disease control depends upon understanding the host-pathogen interaction that occurs in the field. Addressing the broader impact of improved disease control is a formidable task, as many environmental factors (both biotic and abiotic) act upon plants under field conditions. A first and critical step toward bridging the gap between understanding the molecular basis of P. infestans biology and pathogenicity and developing new disease management strategies is to study the host-pathogen interaction in the field. By utilizing the information identified in laboratory studies, we can determine how the more complex agricultural setting alters the infection process and disease spread.

The first genomics-type field studies of the late blight host-pathogen interaction are underway in the laboratories of C. D. Smart and W. E. Fry at Cornell University. A variety of laboratory experiments that follow gene expression in the host (potato or tomato) and $P$. infestans during infection have been performed $(6,10,49)$. Expression profiling of plant genes following inoculation with $P$. infestans in the field under typical growing conditions will allow comparisons between laboratory and field data. This will help establish the relevance of the laboratory experiments to field conditions, as well as evaluate the contribution of particular plant and pathogen genes to disease under a diversity of environmental conditions. Recently, Smart, Fry, and colleagues have successfully utilized microarray analysis to follow expression patterns of approximately 12,000 tomato genes over time. Using the tomato$P$. infestans interaction, the gene expression profiles of plants are being examined under a diversity of conditions. Preliminary analyses have shown that approximately $5 \%$ of the genes were differentially expressed when comparing tissues from diseased and healthy plants in the field. This suggests that despite the considerable variability that occurs in agricultural settings, it remains possible to identify consistent patterns of changes in plant gene expression.

Future experiments will look at pathogen progress in the field. With the availability of $P$. infestans microarrays, it will be possible to study gene expression in the pathogen as well as the host. While individual environmental parameters can be studied in growth chamber experiments, field experiments offer opportunities to compare potential control strategies under multiple environmental conditions. To accomplish these goals, plant pathologists with expertise in the design and statistical analysis of field experiments need to work together with pathologists with expertise in genomics to identify putative control strategies. Multidisciplinary collaborations such as these will allow the identification and deployment of novel disease management strategies.

\section{Conclusion}

For plant pathology to continue to prosper as a significant field of biology, it is critical that genomics becomes a cornerstone of plant pathology research. In this article, we illustrated the actual and potential impact of genomics on plant pathology by focusing on late blight of potato and tomato, one of the most important plant diseases. We provided an update on genomics of $P$. infestans and discussed how it is leading to improvements in basic studies and management of this disease. Clearly $P$. infestans genomics is still in its infancy, and we do not have answers to all the questions. However, with the application of technologies made possible by genomics, the pace of discovery has greatly accelerated. Multidisciplinary approaches that combine genomics with traditional areas of plant pathology brighten the future of late blight management. We are optimistic that future generations of potato and tomato growers will not have to cope with the same problems caused by late blight that they are dealing with today.

\section{Acknowledgments}

We thank Bill Fry, Wolfram Koeller, two anonymous reviewers, and the editor for improving the manuscript, and Tea Meulia and the staff of the Molecular and Cellular Imaging Center at the Ohio Agricultural Research and Development Center, Wooster, for assistance with electron microscopy. Research in the Kamoun laboratory is supported by NSF Plant Genome grant DBI-0211659, USDANRI project OHO00963-SS, and state and federal funds appropriated to OARDC, the Ohio State University. Research in the Smart laboratory is supported by USDA-NRI project 2002-3531912651, and state and federal funds appropriated to the New York State Agricultural Experiment Station, Cornell University.

\section{Literature Cited}

1. Adler, N. E., Chacon, G., Flier, W. G., and Forbes, G. A. 2002. The andean fruit crop, pear melon (Solanum muricatum) is a common host for A1 and A2 strains of Phytophthora infestans in Ecuador. Plant Pathol. 51:802.

2. Adler, N. E., Erselius, L. J., Chacon, M. G., Flier, W. G., Ordonez, M. E., Kroon, L. P. N. M., and Forbes, G. A. 2004. Genetic diversity of Phytophthora infestans sensu lato in Ecuador provides new insight into the origin of this important plant pathogen. Phytopathology 94:154-162.

3. Ah Fong, A. M., and Judelson, H. S. 2003. Cell cycle regulator $\mathrm{Cdc14}$ is expressed during sporulation but not hyphal growth in the fungus-like oomycete Phytophthora infestans. Mol. Microbiol. 50:487-494.

4. Anonymous. 2004. Late blight in Papua New Guinea. Global Initiative on Late Blight (GILB) Newsl. 23:4-5.

5. Armstrong, M. R., Whisson, S. C., Pritchard, L., Bos, J. I. B., Venter, E., Avrova, A. O., Rehmany, A. P., Böhme, U., Brooks, K., Cherevach, I., Hamlin, N., White, B., Fraser, A., Lord, A., Quail, M. A., Churcher, C., Hall, N., Berriman, M., Huang, S., Kamoun, S., Beynon, J. L., and Birch, P. R. J. 2005. An ancestral oomycete locus contains late blight avirulence gene $A v r 3 a$, encoding a protein that is 
recognised in the host cytoplasm. Proc. Natl. Acad. Sci. USA. In press.

6. Avrova, A. O., Taleb, N., Rokka, V. M., Heilbronn, J., Campbell, E., Hein, I., Gilroy, E. M., Cardle, L., Bradshaw, J. E., Stewart, H. E., Jaufeerally-Fakim, Y., Loake, G., and Birch, P. R. J. 2004. Potato oxysterol binding protein and cathepsin B are rapidly up-regulated in independent defence pathways that distinguish $R$ gene-mediated and field resistances to Phytophthora infestans. Mol. Plant Pathol. 5:45-

7. Baldauf, S. L., Roger, A. J., Wenk-Siefert, I., and Doolittle, W. F. 2000. A kingdom-level phylogeny of eukaryotes based on combined protein data. Science 290:972-977.

8. Ballvora, A., Ercolano, M. R., Weiss, J., Meksem, K., Bormann, C. A., Oberhagemann, P., Salamini, F., and Gebhardt, C. 2002. The RI gene for potato resistance to late blight (Phytophthora infestans) belongs to the leucine zipPlant J. 30:361-371.

9. Birch, P. R. J., Avrova, A. O., Armstrong, M., Venter, E., Taleb, N., Gilroy, E. M., Phillips, M. S., and Whisson, S. C. 2003. The potatoPhytophthora infestans interaction transcriptome. Can. J. Plant Pathol. 25:226-231.

10. Birch, P. R. J., Avrova, A. O., Duncan, J. M., Lyon, G. D., and Toth, R. L. 1999. Isolation of potato genes that are induced during an early stage of the hypersensitive response to Phytophthora infestans. Mol. Plant-Microbe Interact. 12:356-361.

11. Birch, P. R. J., and Whisson, S. 2001. Phyper/NBS/LRR class of plant resistance genes.

tophthora infestans enters the genomics era. Mol. Plant Pathol. 2:257-263.

12. Bos, J. I. B., Armstrong, M., Whisson, S. C., Torto, T., Ochwo, M., Birch, P. R. J., and Kamoun, S. 2003. Intraspecific comparative genomics to identify avirulence genes from Phytophthora. New Phytol. 159:63-72.

13. Coffey, M. D., and Wilson, U. E. 1983. Histology and cytology of infection and disease caused by Phytophthora. Pages 289-301 in: Phytophthora: Its Biology, Taxonomy, Ecology, and Pathology. D. C. Erwin, S. BartnickiGarcia, and P. H. Tsao, eds. American Phytopathological Society, St. Paul, MN.

14. Dangl, J. L., and Jones, J. D. 2001. Plant pathogens and integrated defence responses to infection. Nature 411:826-833.

15. Duncan, J. M. 1999. Phytophthora-An abiding threat to our crops. Microbiol. Today 26:114116.

16. Erwin, D. C., and Ribeiro, O. K. 1996. Phytophthora Diseases Worldwide. American Phytopathological Society, St. Paul, MN.

17. Flier, W. G., Grunwald, N. J., Kroon, L. P. N. M., van den Bosch, T. B. M., Garay-Serrano, E., Lozoya-Saldana, H., Bonants, P. J. M., and Turkensteen, L. J. 2002. Phytophthora ipomoeae sp. nov., a new homothallic species causing leaf blight on Ipomoea longipedunculata in the Toluca Valley of central Mexico. Mycol. Res. 106:848-856

18. Flier, W. G., van den Bosch, G. B. M., and Turkensteen, L. J. 2003. Epidemiological importance of Solanum sisymbriffolium, S. nigrum and $S$. dulcamara as alternative hosts for

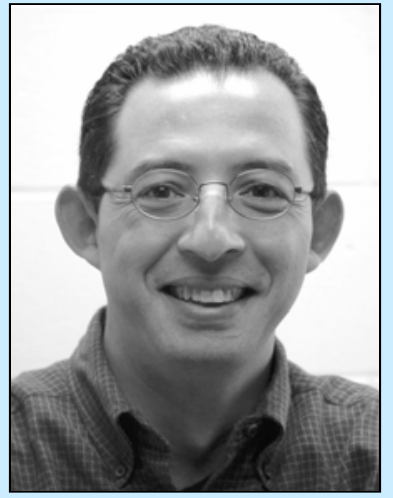

Sophien Kamoun

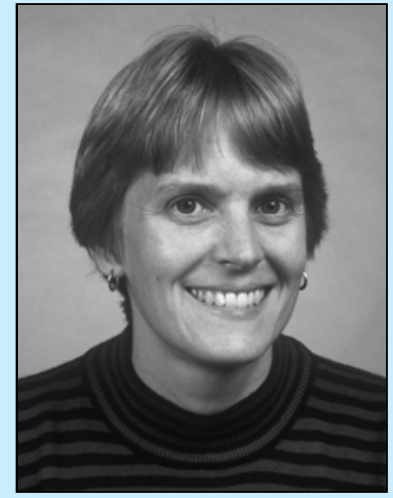

Christine D. Smart
Dr. Kamoun is an associate professor of oomycete molecular genetics at the Ohio State University, Department of Plant Pathology, Wooster campus. He received his B.S. degree from Pierre and Marie Curie University, Paris, France, and his Ph.D. from the University of California at Davis. He then was a postdoctoral fellow at the NSF Center for Engineering Plants for Resistance Against Pathogens, UC Davis, and at the Department of Phytopathology, Wageningen University, The Netherlands. Dr. Kamoun joined the OSU faculty in 1998, where he has been studying the molecular genetics of oomycete-host interactions, particularly those involving Phytophthora spp. He co-teaches two graduate courses at OSU: Agricultural Genomics and Plant-Microbe Interactions.

Dr. Smart is an assistant professor of vegetable pathology in the Department of Plant Pathology, Cornell University, New York State Agricultural Experiment Station in Geneva, NY. She received her B.S. and Ph.D. degrees from Michigan State University. Postdoctoral experiences were at the Departments of Plant Pathology, University of California, Davis, and Cornell University, where she investigated prokaryotic pathogens of fruit crops and Phytophthora infestans, respectively. Dr. Smart joined the Cornell faculty in 2003, with research and extension programs which utilize genomic technologies to identify and improve control strategies for vegetable diseases.
Phytophthora infestans. Plant Pathol. 52:595603.

19. Fry, W. E., and Goodwin, S. B. 1997. Re-emergence of potato and tomato late blight in the United States. Plant Dis. 81:1349-1357.

20. Garelik, G. 2002. Agriculture. Taking the bite out of potato blight. Science 298:1702-1704

21. Gibson, G., and Muse, S. V. 2002. A primer of Genome Science. Sinauer Associates, Inc., Sunderland, MA

22. Goodwin, S. B. 1997. The population genetics of Phytophthora. Phytopathology 87:462-473.

23. Goodwin, S. B., and Fry, W. E. 1994. Genetic analyses of interspecific hybrids between Phy tophthora infestans and Phytophthora mirabilis. Exp. Mycol. 18:20-32.

24. Helgeson, J. P., Pohlman, J. D., Austin, S., Haberlach, G. T., Wielgus, S. M., Ronis, D. Zambolim, L., Tooley, P., Mcgrath, J. M. James, R. V., and Stevenson, W. R. 1998. Somatic hybrids between Solanum bulbocastanum and potato; A new source of resistance to late blight. Theor. Appl. Genet. 96:738-742.

25. Huang, S., van der Vossen, E. H. K., Vleeshouwers, V., Zhang, N., Borm, T., van Eck, H. B. B. E. J., and Visser, R. 2005. Comparative genomics enabled the isolation of the $R 3 a$ late blight resistance gene in potato. Plant J. In press.

26. Huitema, E., Bos, J. I. B., Tian, M., Win, J., Waugh, M. E., and Kamoun, S. 2004. Linking sequence to phenotype in Phytophthora-plant interactions. Trends Microbiol. 12:193-200.

27. Huitema, E., Vleeshouwers, V. G. A. A., Francis, D. M., and Kamoun, S. 2003. Active defense responses associated with nonhost resistance of Arabidopsis thaliana to the oomycete pathogen Phytophthora infestans. Mol. Plant Pathol. 4:487-500.

28. Judelson, H. S., and Blanco, F. A. 2005. The spores of Phytophthora: Weapons of the plant destroyer. Nature Rev. Microbiol. 3:47-58.

29. Judelson, H. S., and Tooley, P. W. 2000. Enhanced polymerase chain reaction methods for detecting and quantifying Phytophthora infestans in plants. Phytopathology 90:11121119.

30. Kamoun, S. 2001. Nonhost resistance to Phytophthora: Novel prospects for a classical problem. Curr. Opin. Plant Biol. 4:295-300.

31. Kamoun, S. 2003. Molecular genetics of pathogenic oomycetes. Eukaryotic Cell 2:191-199.

32. Kamoun, S., Dong, S., Hamada, W., Huitema E., Kinney, D., Morgan, W. R., Styer, A., Testa, A., and Torto, T. 2002. From sequence to phenotype: Functional genomics of Phytophthora Can. J. Plant Pathol. 24:6-9.

33. Kamoun, S., Hraber, P., Sobral, B., Nuss, D., and Govers, F. 1999. Initial assessement of gene diversity for the oomycete pathogen Phytophthora infestans based on expressed sequences. Fungal Genet. Biol. 28:94-106.

34. Kamoun, S., Huitema, E., and Vleeshouwers, V. G. A. A. 1999. Resistance to oomycetes: A general role for the hypersensitive response? Trends Plant Sci. 4:196-200.

35. Kamoun, S., van West, P., Vleeshouwers, V. G., de Groot, K. E., and Govers, F. 1998. Resistance of Nicotiana benthamiana to Phy tophthora infestans is mediated by the recognition of the elicitor protein INF1. Plant Cell 10:1413-1426.

36. Kim, K. S., and Judelson, H. S. 2003. Sporangium-specific gene expression in the oomycete phytopathogen Phytophthora infestans. Eukaryotic Cell 2:1376-1385.

37. Latijnhouwers, M., de Wit, P. J. G. M., and Govers, F. 2003. Oomycetes and fungi: Similar weaponry to attack plants. Trends Microbiol. 11:462-469.

38. Liu, Z., Bos, J. I. B., Armstrong, M., Whisson, S. C., da Cunha, L., Torto-Alalibo, T., Win, J. Avrova, A. O., Wright, F., Birch, P. R. J., and Kamoun, S. Patterns of diversifying selection in the phytotoxin-like scr74 gene family of 
Phytophthora infestans. Mol. Biol. Evol. 22:659-672.

39. McLeod, A., Smart, C. D., and Fry, W. E. 2002. Characterization of 1,3-beta glucanase and 1,3;1,4-beta glucanase genes from Phytophthora infestans. Fungal Genet. Biol. 38:250-263.

40. Michelmore, R. W. 2003. The impact zone: Genomics and breeding for durable disease resistance. Curr. Opin. Plant Biol. 6:397-404.

41. Nicholls, H. 2004. Stopping the rot. PLOS Biol. 2:891-895.

42. Ordonez, M. E., Hohl, H. R., Velasco, J. A., Ramon, M. P., Oyarzun, P. J., Smart, C. D., Fry, W. E., Forbes, G. A., and Erselius, L. J. 2000. A novel population of Phytophthora, similar to $P$. infestans, attacks wild Solanum species in Ecuador. Phytopathology 90:197-202.

43. Ospina-Giraldo, M. D., and Jones, R. W. 2003. Characterization of the glucose-6-phosphate isomerase gene in Phytophthora infestans reveals the presence of multiple alleles. Fungal Genet. Biol. 40:197-206.

44. Randall, T. A., Dwyer, R. A., Huitema, E., Beyer, K., Cvitanich, C., Kelkar, H., Ah Fong, A. M. V., Gates, K., Roberts, S., Yatzkan, E., Gaffney, T., Law, M., Testa, A., Torto, T., Zhang, M., Zheng, L., Mueller, E., Windass, J., Binder, A., Birch, P. R. J., Gisi, U., Govers, F., Gow, N., Mauch, F., van West, P., Waugh, M., Yu, J., Boller, T., Kamoun, S., Lam, S. T., and Judelson, H. S. 2005. Large-scale gene discovery in the oomycete Phytophthora infestans reveals likely components of phytopathogenicity shared with true fungi. Mol. Plant-Microbe Interact. 18:229-243.

45. Ristaino, J. B. 2002. Tracking historic migrations of the Irish potato famine pathogen, Phytophthora infestans. Microbes Infect.
4:1369-1377.

46. Schiermeier, Q. 2001. Russia needs help to fend off potato famine, researchers warn. Nature 410:1011.

47. Shattock, R. C. 2002. Phytophthora infestans: Populations, pathogenicity and phenylamides. Pest Manag. Sci. 58:944-950.

48. Smart, C. D., and Fry, W. E. 2001. Invasions by the late blight pathogen: Renewed sex and enhanced fitness. Biol. Invas. 3:235-243.

49. Smart, C. D., Myers, K. L., Restrepo, S., Martin, G. B., and Fry, W. E. 2003. Partial resistance of tomato to Phytophthora infestans is not dependent upon ethylene, jasmonic acid, or salicylic acid signaling pathways. Mol PlantMicrobe Interact. 16:141-148.

50. Sogin, M. L., and Silberman, J. D. 1998. Evolution of the protists and protistan parasites from the perspective of molecular systematics. Int. J. Parasitol. 28:11-20.

51. Song, J., Bradeen, J. M., Naess, S. K., Raasch, J. A., Wielgus, S. M., Haberlach, G. T., Liu, J., Kuang, H., Austin-Phillips, S., Buell, C. R., Helgeson, J. P., and Jiang, J. 2003. Gene $R B$ cloned from Solanum bulbocastanum confers broad spectrum resistance to potato late blight. Proc. Natl. Acad. Sci. USA 100:9128-9233.

52. Stein, J. M., and Kirk, W. W. 2003. Variations in the sensitivity of Phytophthora infestans isolates from different genetic backgrounds to dimethomorph. Plant Dis. 87:1283-1289.

53. Stein, J. M., and Kirk, W. W. 2004. The generation and quantification of resistance to dimethomorph in Phytophthora infestans. Plant Dis. 88:930-934

54. Tani, S., Kim, K. S., and Judelson, H. S. 2005. A cluster of NIF transcriptional regulators with divergent patterns of spore-specific expression in Phytophthora infestans. Fungal
Genet. Biol. 42:42-50.

55. Tani, S., Yatzkan, E., and Judelson, H. S. 2004 Multiple pathways regulate the induction of genes during zoosporogenesis in Phytophthora infestans. Mol. Plant-Microbe Interact. 17:330337.

56. Tanzer, M. M., Adachi, K., Allen, K., DeZwaan, T., Frank, S., Hamer, L., Heiniger, R. Nelson, G., Peoples, K., Skalchunes, A., Pan, H., and Shuster, J. R. 2003. Targeted fungicide discovery. (Abstr.) Phytopathology 93:S114.

57. Tian, M., Huitema, E., da Cunha, L., TortoAlalibo, T., and Kamoun, S. 2004. A Kazallike extracellular serine protease inhibitor from Phytophthora infestans targets the tomato pathogenesis-related protease P69B. J. Biol. Chem. 279:26370-26377.

58. Torto, T., Li, S., Styer, A., Huitema, E., Testa, A., Gow, N. A. R., van West, P., and Kamoun, S. 2003. EST mining and functional expression assays identify extracellular effector proteins from Phytophthora. Genome Res. 13:675-685.

59. Torto, T. A., Rauser, L., and Kamoun, S. 2002. The pipgl gene of the oomycete Phytophthora infestans encodes a fungal-like endopolygalacturonase. Curr. Genet. 40:385-390.

60. van der Vossen, E., Sikkema, A., Hekkert, B. L., Gros, J., Stevens, P., Muskens, M., Wouters, D., Pereira, A., Stiekema, W., and Allefs, S. 2003. An ancient $R$ gene from the wild potato species Solanum bulbocastanum confers broad-spectrum resistance to Phytophthora in festans in cultivated potato and tomato. Plant $\mathrm{J}$. 36:867-882.

61. Vleeshouwers, V. G., van Dooijeweert, W. Govers, F., Kamoun, S., and Colon, L. T. 2000 The hypersensitive response is associated with host and nonhost resistance to Phytophthora infestans. Planta 210:853-864. 